\title{
Response characteristics of water level dynamic of the Baiyangdian Wetland to climate change and human activities
}

\author{
Xiaofan Qi*, Dechao Yin, Yonghui An, Yushan Wang, Lei Gong \\ Center for Hydrogeology and Environmental Geology Survey, China Geological Survey, Baoding, Hebei 071051, China
}

\begin{abstract}
Water level dynamics of Wetlands are influenced by both climate change and human activities. Understanding the influence characteristics is important for the management of wetland water resources and ecology. Based on the water level dynamic and precipitation of the Baiyangdian Wetland, and the NPI index, the paper analyzes the response characteristics of the water level dynamic to the precipitation, and the teleconnections between the water level dynamic and the NPI by adopting method of wavelet analysis. Results show that climate change plays an important role on the response of the water level dynamic to the precipitation and also to the NPI, and human activities can significantly change the response characteristics. The response time lags of the water level dynamics to the NPI is longer than that of the water level dynamics to the precipitations, which indicates that the wetland precipitation might be partially influenced by the NPI. The knowledge of the response characteristics obtained in the paper is beneficial for water conservancy and control of the wetland, and is favorable for the sustainable development of its eco-environment.
\end{abstract}

\section{Introduction}

Response of hydrologic processes to climate change is an important research field on aspect of climate change, and the hydrologic factors are the main driving forces for the formation and maintenance of wetlands [1]. As the largest wetland in the North China Plain, the Baiyangdian Wetland (BW) plays an important role in maintaining water balance and ecological health of the plain [2]. In the past few decades, the water level dynamic of the BW have changed dramatically as a result of both climate variability and human activities, inducing a series of water and eco-environment issues.

Responses of the BW to climate change and human activities have been studied. Liu et al. (2007) analyzed the variations of meteorology, hydrology and ecologic systems of the BW, and concluded that climate change played a dominating role on the change of the wetland and human activities intensified the trends [1]. Hu et al. (2012) quantified the impacts of climate variability and human activities on streamflow of the inflow rivers of the BW [2]. Feng et al. (2017) studied response of groundwater level regime near the $\mathrm{BW}$ to precipitation and NPI, concluded that in addition to human activities, the main meteorological influence factor is precipitation [3]. Quantitative analysis of response characteristics of water level dynamics of the BW to climate change and human activities is relatively deficient. The response characteristics are studied in this paper, aiming to help improve integrated watershed management in the future.

\section{Materials and Methodology}

\subsection{Site description}

The Baiyangdian Wetland is located in the northern part of the North China Plain, and is the fan margin depression of the intersection of the alluvial and pluvial fans of the Yongding River and the Hutuo River in front of the Taihang Mountain (Fig.1). It belongs to the Daqing River System of the Haihe River Basin, extending from $115^{\circ} 45^{\prime} \mathrm{E}$ to $116^{\circ} 07^{\prime} \mathrm{E}$ of longitude and $38^{\circ} 44^{\prime} \mathrm{N}$ to $38^{\circ} 59^{\prime} \mathrm{N}$ of latitude, with a total area of 366 square kilometers, and more than 3,700 ravines and about 143 sub-lakes. It is well known as the "Pearl of North China".

The BW belongs to the warm temperate semi-humid continental monsoon climate zone, which has four distinct seasons. The annual average temperature is $12.2^{\circ} \mathrm{C}$, and the extreme maximum temperature is $40.7^{\circ} \mathrm{C}$, and the extreme minimum temperature is $-26.7^{\circ} \mathrm{C}$. The average annual precipitation is $529.7 \mathrm{~mm}$. 


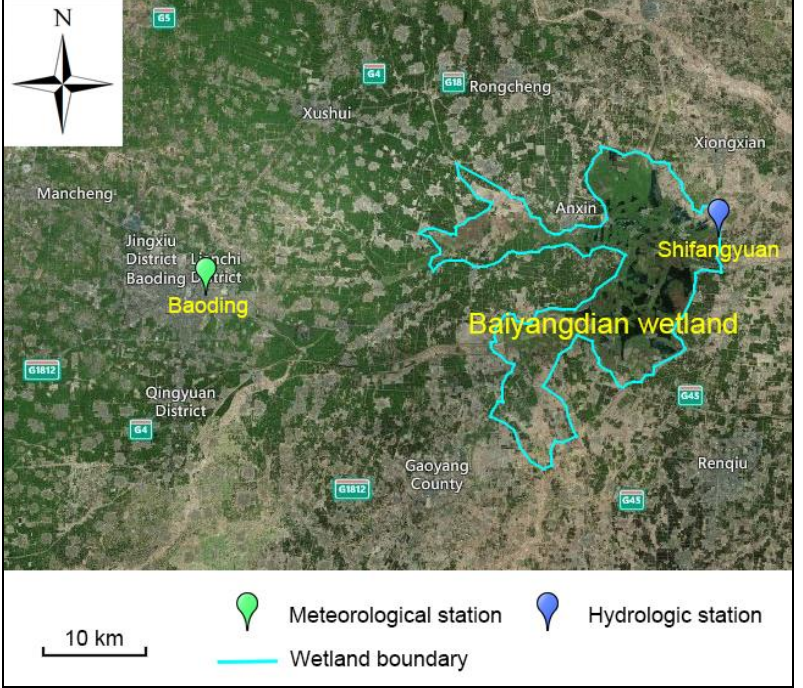

Fig.1. General map of the study area

\subsection{Data}

\subsubsection{Water level dynamic, precipitation and NPI}

The hydrologic station of the water level dynamic of the BW used in this paper is the Shifangyuan station, which is established in 1919 (Fig.1). The chosen dynamic period is from 1955 to 2015 , in order to be consistent with the precipitation data. The monthly dynamic data from 1955 to 1996 is from the Anxi County Annals, while the other part is from Baoding water conservancy Bureau.

Monthly precipitation monitoring data of Baoding meteorological station which locates in the Daqing River System and stands for the precipitation of the system is used in this paper. The meteorological data is from China Meteorological Data Service Center (http://data.cma.cn).

The North Pacific Index (NPI) is an area-weighted sea-level pressure of $30^{\circ} \mathrm{N}-65^{\circ} \mathrm{N}, 160^{\circ} \mathrm{E}-140^{\circ} \mathrm{W}$, and is from the National Center for Atmospheric Research (NCAR). The Trenberth and Hurrell dataset is chosen in this paper. The index is a representation of the law of inter-annual change in the climate system of the North Pacific area.

\subsubsection{Selection of study periods}

The precipitation can be divided into four periods and there are significant differences among the periods. The average precipitation from 1955 to 1967 is $630.35 \mathrm{~mm}$, while the precipitation from 1968 to 1984 is $477.06 \mathrm{~mm}$. The average precipitation from 1985 to 1996 is $609.74 \mathrm{~mm}$, while the precipitation from 1997 to 2015 is $451.47 \mathrm{~mm}$ (Fig.2). Several reservoirs were built on the inflow rivers of the BW. The Longmen reservoir was built in 1958, and the Wangkuai reservoir, the Xidayang reservoir and the Angezhuang reservoir were built in 1960. The reservoirs significantly changed the inflows of the BW. Three study periods which were 1955-1959, 1990-1994 and 2011-2015, were selected in this paper to analyze the correlations of the above three time series, considering different characteristics of climate change and human activities comprehensively.

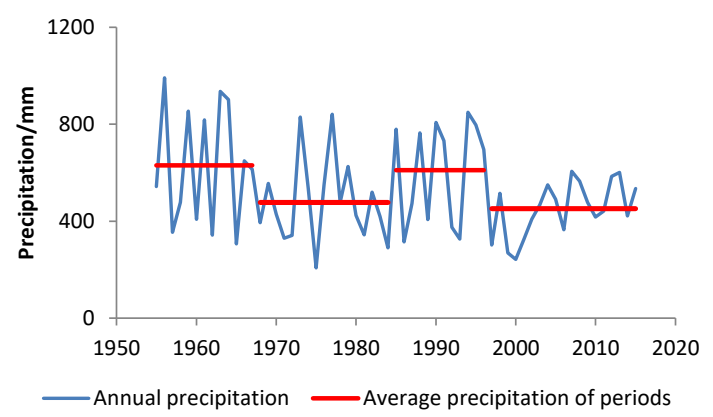

Fig.2. Precipitation of the Baoding meteorological station

\subsection{Methods}

Wavelet analysis was adopted in this paper, including Continuous Wavelet Transform (CWT) and Cross Wavelet Transform (XWT). The idea of the CWT is to apply the wavelet as a bandpass filter to the studied time series. The wavelet is stretched in time domain by varying the time scale. XWT reveals high common power areas of the two studied time series. The methods and computer programs are from Torrence and Compo [5], and Grinsted et al. [6].

\section{Results and discussion}

\subsection{Periodicities of the time series}

CWTs of the water level dynamic, precipitation and NPI of 1955-2015 were proceeded to analyze the main oscillation periods. Results show that all the three studied time series have significant periods of about 1 a.

\subsection{Responses of water level changes to precipitation}

XWTs of water level dynamics and precipitations of 1955-1959, 1990-1994 and 2011-2015 were proceeded to analyze the main resonance periods, significant time and time lags (Fig.3). The main resonance periods of the three selected periods are about the same, and the significant time all have long duration.

The time lags of 1990-1994 and 2011-2015 are much longer than that of 1955-1959 (Table 1), which shows significant influence of human activities. As the reservoirs were built, the inflows of the rivers were delayed artificially, and the water level dynamics of the BW were delayed simultaneously.

To illustrate the influence of climate change to the water level dynamics, the year of 1956 and 1958 of the XWTs were selected to analyze. The precipitation of the year of 1956 is $991.3 \mathrm{~mm}$, which is much greater than that of 1958, which is $477.5 \mathrm{~mm}$. XWTs show that the time lag of 1956 is $73.1 \pm 4.0 \mathrm{~d}$, and that of 1958 is $106.7 \pm 4.9 \mathrm{~d}$. With greater precipitation, the response of water level dynamic to precipitation is much faster. It should be aware that the response of the water level 
dynamic to precipitation is influenced by both the precipitation on the wetland directly and the precipitation on the inflow river-basins, and the latter one plays a dominant role for the studied two years.
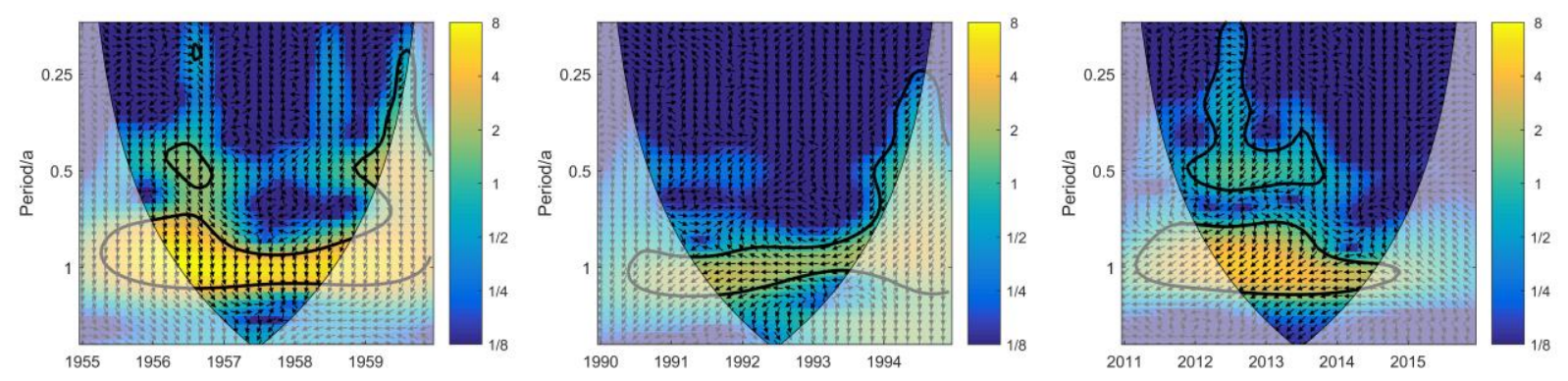

The yellow and blue colors stand for high and low values of wavelet spectra respectively. Dark and light of the colors explain comparative variance of the wavelet spectra. The thick black lines are the 5\% significance level, and the less intense colors indicate

the cone of influence (COI). The phase angle (shown as black arrows) identifies the phase relation between two series, with a right-pointing arrow indicating an in-phase relation, and a left-pointing arrow indicating an anti-phase relation, and arrows pointing up or down show that one time series is leading the other by $90^{\circ}$.

Fig.3 XWTs of water level dynamics and precipitations

Table 1. Periodicities of XWTs of water level dynamics and precipitations

\begin{tabular}{cccc}
\hline Time series & Main resonance periods [a] & Significant time [a] & Time lag [d] \\
\hline $1955-1959$ & $0.82-1.16$ & $1955-1959$ & $86.4 \pm 14.4$ \\
$1990-1994$ & $0.87-1.23$ & $1990-1994$ & $177.8 \pm 17.7$ \\
$2011-2015$ & $0.73-1.16$ & $2011-2014$ & $142.3 \pm 31.5$ \\
\hline
\end{tabular}

\subsection{Teleconnections between water level changes and NPI}

XWTs of water level dynamics and NPI are proceeded to analyze the teleconnections characteristics, including the main resonance periods, the significant time and the time lags (Fig.4). The main resonance periods of the three selected periods are about $1 \mathrm{a}$, and the significant time all have long duration.

The time lags of 1990-1994 and 2011-2015 are much
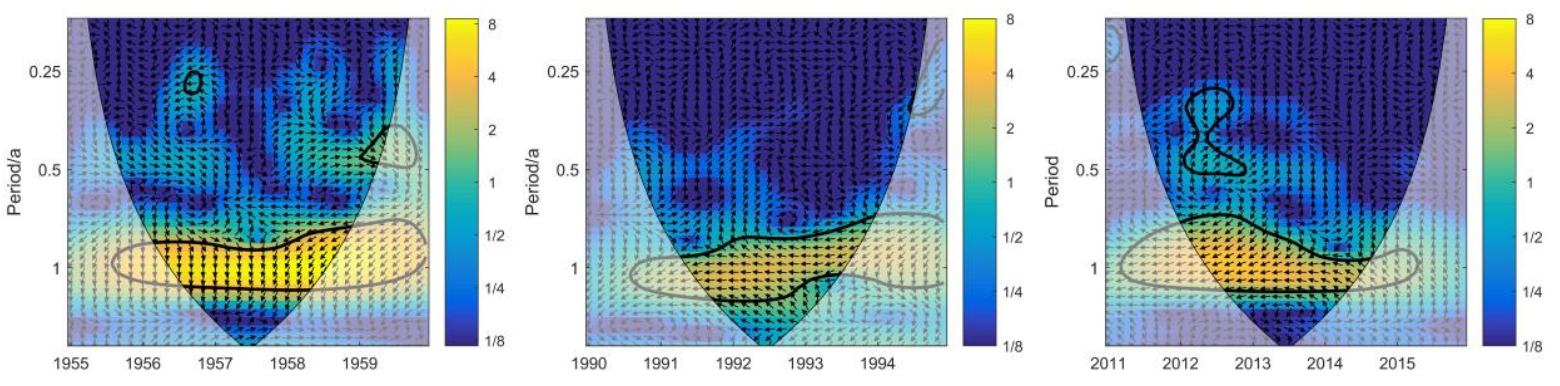

Fig.4. XWTs of water level dynamics and NPI

Table 2. Periodicities of XWTs of water level dynamics and NPI

\begin{tabular}{cccc}
\hline Time series & Main resonance periods [a] & Significant time [a] & Time lag [a] \\
\hline $1955-1959$ & $0.77-1.16$ & $1956-1959$ & $107.2 \pm 24.0$ \\
$1990-1994$ & $0.73-1.23$ & $1991-1994$ & $188.7 \pm 18.2$ \\
$2011-2015$ & $0.73-1.16$ & $2011-2014$ & $167.9 \pm 26.5$ \\
\hline
\end{tabular}

\section{Conclusions}

Wavelet analysis is helpful to study the response characteristics of water level dynamic to climate change and human activities. The water level dynamic, precipitation of the BW and the NPI have the same significant periods of about $1 \mathrm{a}$, and correlations are found between the time series. Climate change plays an important role on the responses. The greater the precipitations are, the faster the responses are. Human activities such as building reservoirs can significantly change the hydrologic processes. For the water level dynamics studied in this paper, human activities significantly prolong the response times of water level dynamics to precipitations, and also to the climate index NPI. The quantitative response time lags are obtained in the paper, which is beneficial for the water resources 
conservancy and the ecological restoration of the BW.

\section{Acknowledgements}

This work was supported by the China Geological Survey (Project No. DD20190300).

\section{References}

1. C. L. Liu, G. D. Xie, Y. Xiao. Resources and Environment in the Yangtze Basin. 16, 2 (2007).

2. S. S. Hu, C. M. Liu, H. X. Zheng, Z. G. Wang, J. J. Yu. J. Geogr. Sci. 23, 5 (2012).

3. W. Feng, X. F. Qi, H. T. Li, W. P. Li, X. L. Yin. Hydrogeology \& Engineering Geology. 44, 6 (2017).

4. C. Torrence, G. P. Compo. B. Am. Meteorol. Soc. 79, 1 (1998).

5. A. Grinsted, J. C. Moore, S. Jevrejeva. Nonlinear Proc. Geoph. 11, 5/6 (2004). 